\title{
Alkali Cation Doping for Improving the Structural Stability of 2D Perovskite in 3D/2D PSCs
}

Chang Liu, ${ }^{* \dagger, \S}$ Jingsong Sun, ${ }^{\ddagger}$ Wen Liang Tan ${ }^{\ddagger}$ Jianfeng Lu, ${ }^{\S}$ Thomas R. Gengenbach ${ }^{\bar{\top}}$

Christopher R. McNeill,,+ Ziyi Ge ${ }^{\dagger}{ }^{\text {Y }}$ i-Bing Cheng, $\$, / /$ Udo Bach*\$
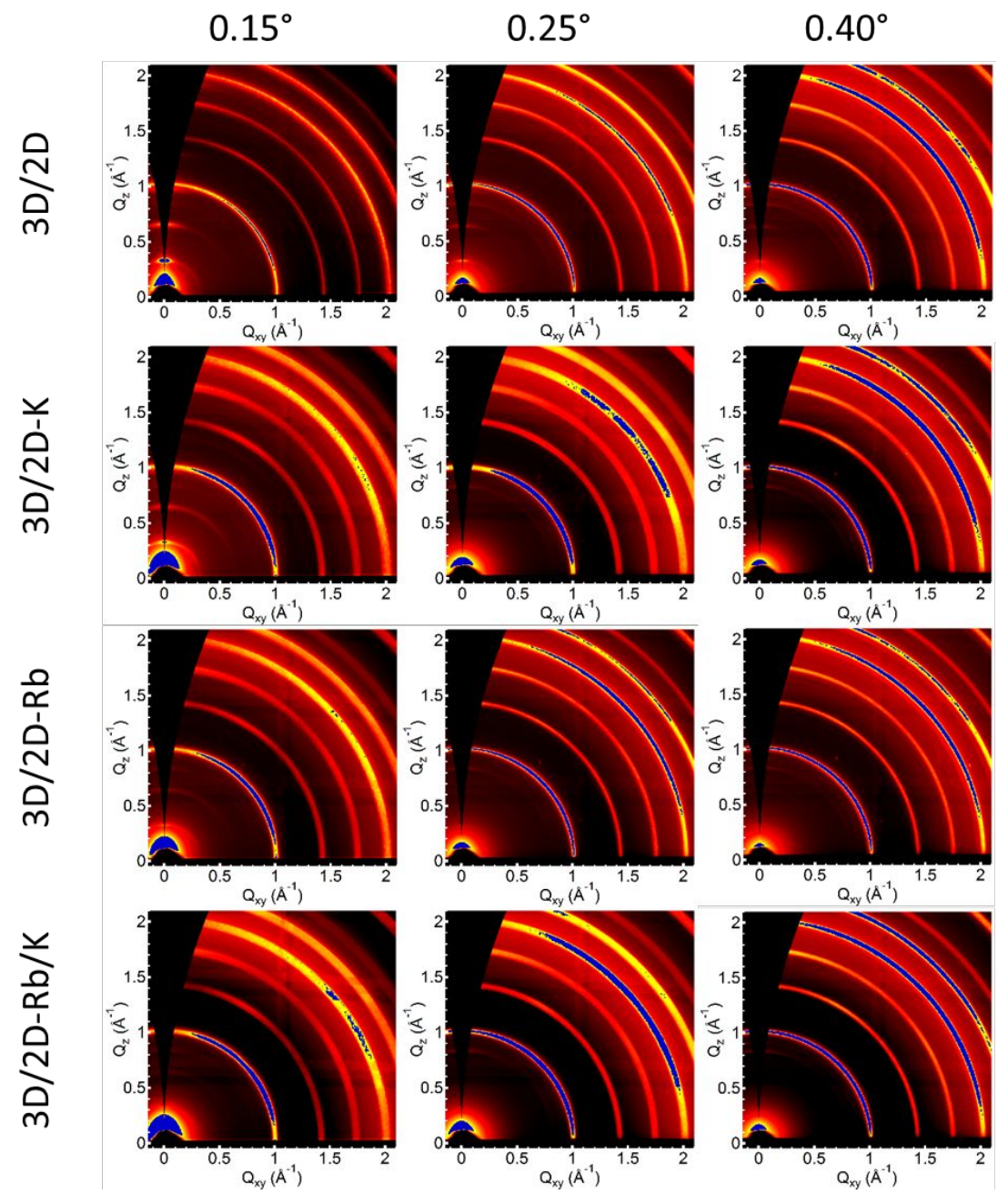

Figure S1. 2D GIWAXS images for 3D/2D, 3D/2D- K, 3D/2D-Rb and 3D/2D-Rb\&K films at incident angle of $0.15^{\circ}, 0.25^{\circ}$ and $0.40^{\circ}$, respectively. 

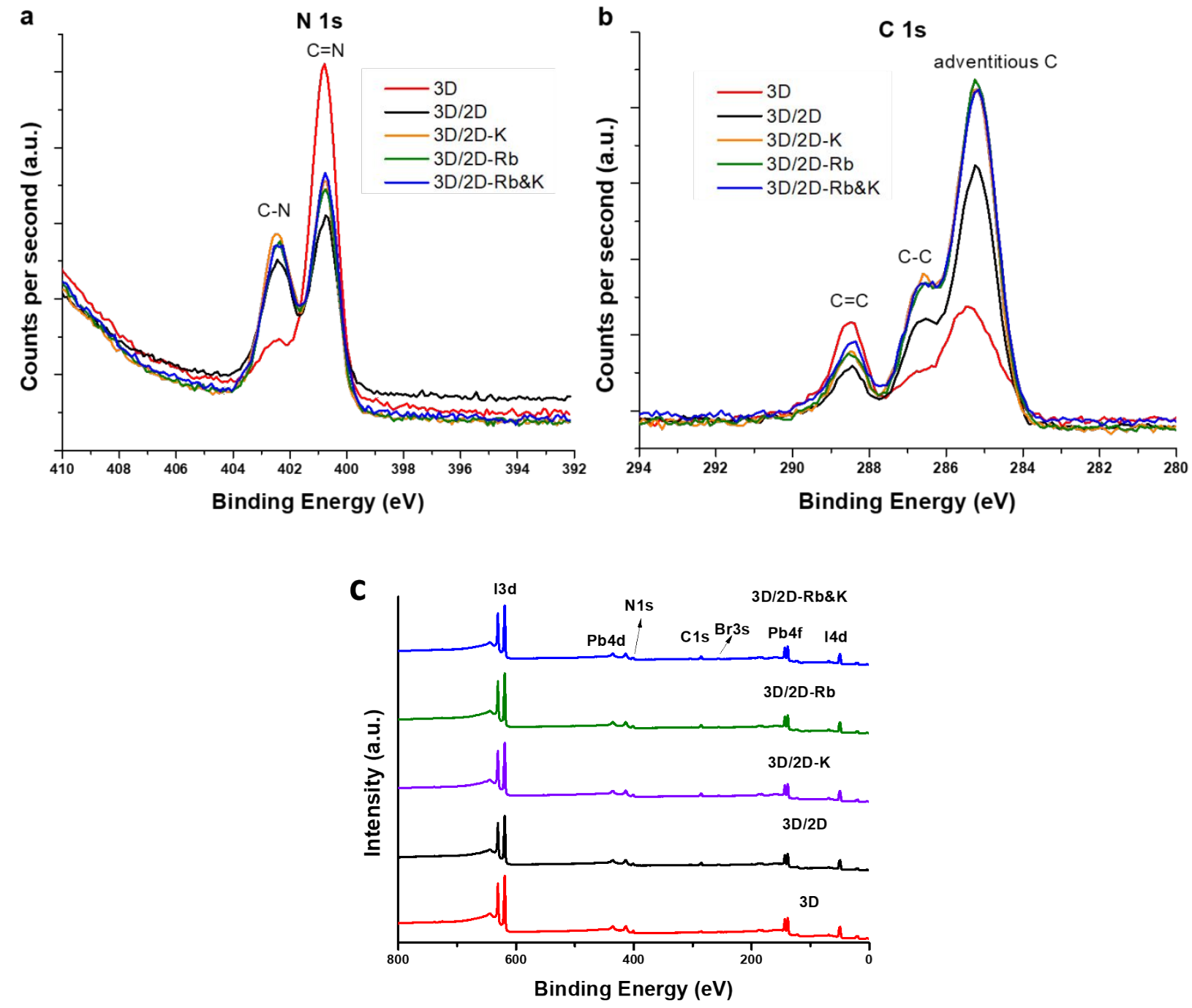

Figure S2. (a) N 1s and (b) C 1s and (c) full survey X-ray photoelectron spectroscopy (XPS) spectra of perovskite films of 3D, 3D/2D, 3D/2D-K, 3D/2D-Rb and 3D/2D-Rb\&K, respective. In all the $3 \mathrm{D} / 2 \mathrm{D}$ samples, BAI concentration is $10 \mathrm{mg} / \mathrm{mL}$ in IPA. For alkali cation-doped $3 \mathrm{D} / 2 \mathrm{D}$ samples, the alkali cation weight ratios with respect to BAI are $5 \% \mathrm{Rb}^{+}, 5 \% \mathrm{~K}^{+}$and $5 \% \mathrm{Rb}^{+}+5 \% \mathrm{~K}^{+}$for 3D/2D-K, 3D/2D-Rb and 3D/2D-Rb\&K, respectively. 
Table S1. Relative atomic ratio from XPS full surveys spectra of perovskite films.

\begin{tabular}{|c|c|c|c|c|c|c|c|c|c|c|c|c|}
\hline \multicolumn{11}{|c|}{ Atomic Ratio (X/Pb) } & \multicolumn{2}{|c|}{ Position (eV) } \\
\hline Sample & $3 \mathrm{D}$ & & $3 \mathrm{D} / 2 \mathrm{D}$ & & 3D/2D-K & & 3D/2D-Rb & & $\begin{array}{l}\text { 3D/2D- } \\
\text { Rb\&KK }\end{array}$ & & & \\
\hline & Mean & Dev. & Mean & Dev. & Mean & Dev. & Mean & Dev. & Mean & Dev. & Mean & Dev. \\
\hline $\mathrm{Pb}$ & 1.000 & 0.000 & 1.000 & 0.000 & 1.000 & 0.000 & 1.000 & 0.000 & 1.000 & 0.000 & & \\
\hline 1 & 2.460 & 0.041 & 2.741 & 0.030 & 2.704 & 0.011 & 2.730 & 0.024 & 2.683 & 0.017 & & \\
\hline Cs & 0.034 & 0.001 & 0.025 & 0.002 & 0.025 & 0.001 & 0.020 & 0.001 & 0.026 & 0.002 & & \\
\hline $\mathrm{Br}$ & 0.230 & 0.008 & 0.289 & 0.006 & 0.310 & 0.020 & 0.267 & 0.009 & 0.296 & 0.004 & & \\
\hline co & 0.290 & 0.024 & 0.001 & 0.001 & 0.000 & 0.000 & 0.004 & 0.004 & 0.000 & 0.000 & 284.47 & 0.14 \\
\hline C2 & 0.570 & 0.001 & 1.956 & 0.058 & 1.918 & 0.017 & 1.995 & 0.044 & 1.887 & 0.003 & 285.27 & 0.14 \\
\hline C3 & 0.252 & 0.005 & 0.779 & 0.021 & 0.783 & 0.010 & 0.735 & 0.036 & 0.724 & 0.005 & 286.69 & 0.08 \\
\hline $\mathrm{C} 4+\mathrm{C} 5$ & 0.593 & 0.025 & 0.442 & 0.007 & 0.423 & 0.011 & 0.436 & 0.003 & 0.432 & 0.003 & 288.48 & 0.02 \\
\hline N1 & 0.895 & 0.036 & 0.613 & 0.010 & 0.599 & 0.003 & 0.617 & 0.010 & 0.642 & 0.018 & 400.71 & 0.02 \\
\hline N2 & 0.122 & 0.005 & 0.467 & 0.004 & 0.515 & 0.005 & 0.467 & 0.020 & 0.491 & 0.016 & 402.46 & 0.05 \\
\hline 0 & 0.077 & 0.004 & 0.075 & 0.014 & 0.065 & 0.005 & 0.069 & 0.018 & 0.077 & 0.013 & & \\
\hline
\end{tabular}



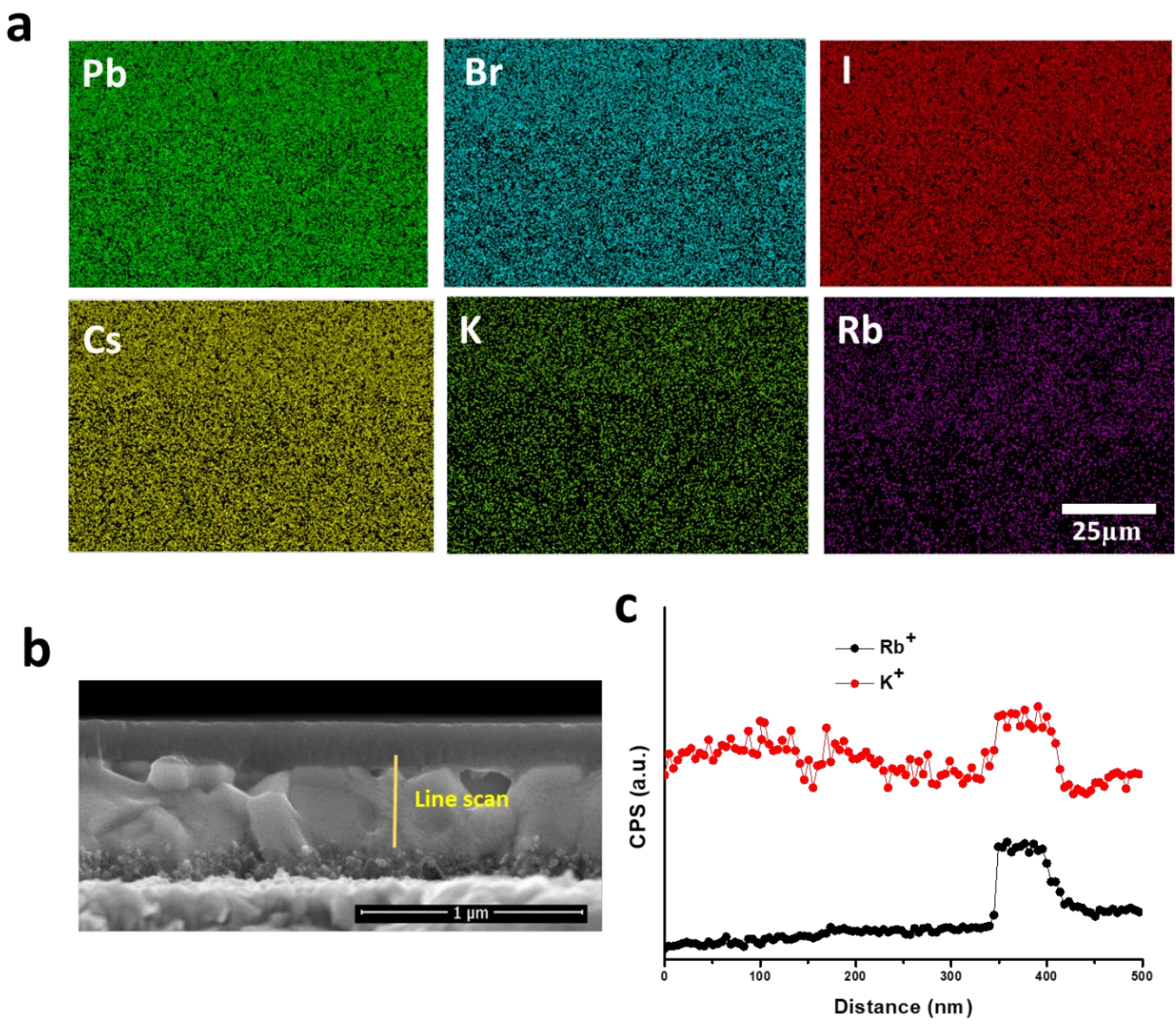

Figure S3. Energy-dispersive X-ray spectroscopy (EDS) (a) mapping of the $\mathrm{Pb}, \mathrm{Br}$, I, Cs, $\mathrm{K}$ and $\mathrm{Rb}$ elements in the 3D/2D-Rb\&K perovskite film (the concentration of $\mathrm{Rb}^{+}$and $\mathrm{K}^{+}$are increased by five-folds, i.e. both are $25 \%$ weight ratio relative to $\mathrm{BAI}$ ); (c) line scan of the Rb and $\mathrm{K}$ elements of the selected area shown in Figure S3b. 

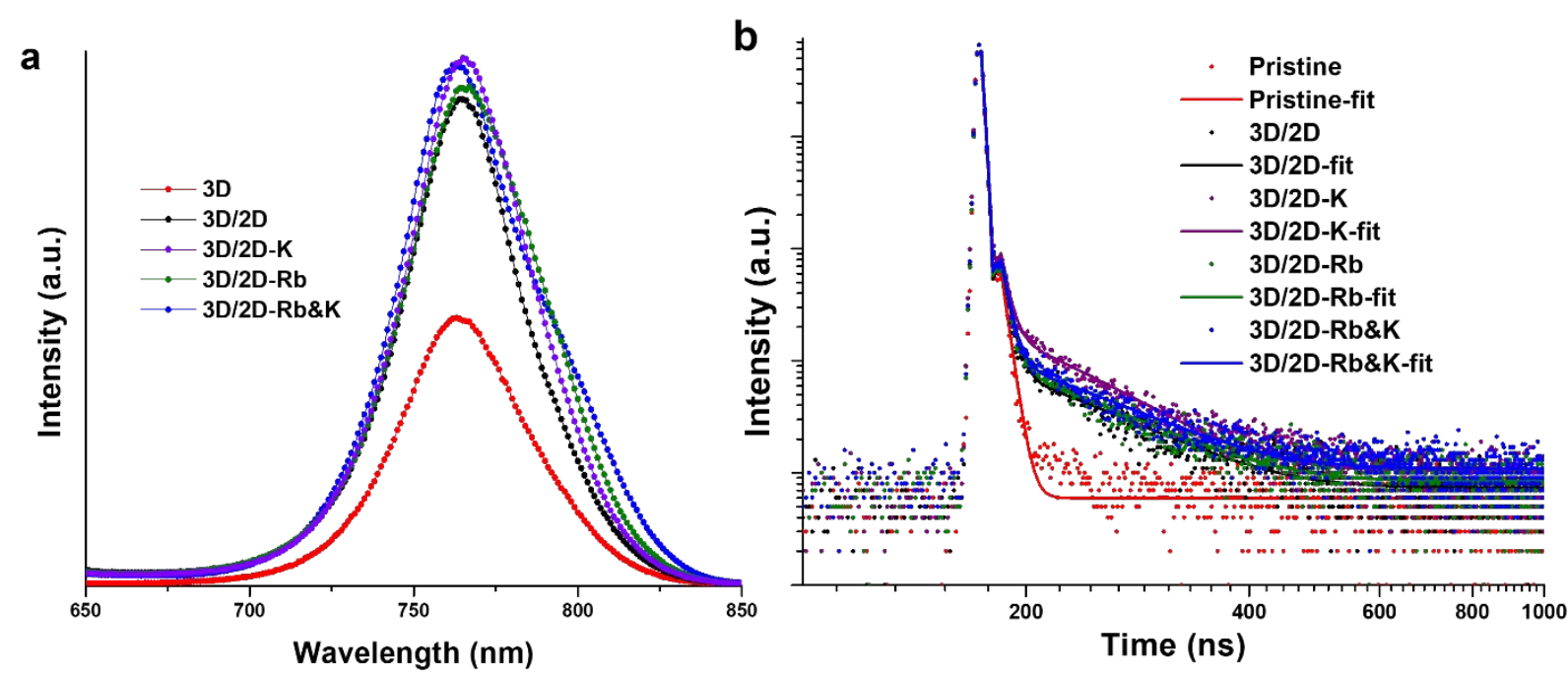

Figure S4. (a) Steady-state and (b) time-resolved photoluminescence spectra of the perovskite films on glass substrate. The samples were excited by $450 \mathrm{~nm}$ pulsed diode laser excitation source.

Table S2. Fitting parameters for the TRPL spectra of the perovskite films shown in Figure S4b.

\begin{tabular}{|c|c|c|c|c|c|}
\hline & $A_{1}$ & $\tau_{1}$ & $A_{2}$ & $\tau_{2}$ & $\langle\tau\rangle$ \\
\hline 3D & 0.52 & 6.5 & 0.89 & 20.2 & 18 \\
\hline $3 D / 2 D$ & 0.28 & 18.3 & 0.93 & 76.2 & 72 \\
\hline 3D/2D-K & 1.32 & 5.3 & 0.87 & 103.2 & 98 \\
\hline 3D/2D-Rb & 1.24 & 6.2 & 0.92 & 87.6 & 85 \\
\hline 3D/2D-Rb\&K & 0.89 & 10.3 & 1.12 & 94.3 & 88 \\
\hline
\end{tabular}

$\mathrm{I}(\mathrm{t})=I_{0}+A_{1} \exp \left(-t / \tau_{1}\right)+A_{2} \exp \left(-t / \tau_{2}\right),\left(\tau_{1}\right.$ and $\tau_{2}$ give the fast and slow decay time constant, $A_{1}$ and $A_{2}$ are fractions of the two decay processes. Average lifetime $\langle\tau\rangle=\alpha_{1} \tau_{1}+\alpha_{2}$ $\tau_{2}, \alpha_{i}={ }^{A_{i}} \tau_{i} / \sum A_{i} \tau_{i}$ 

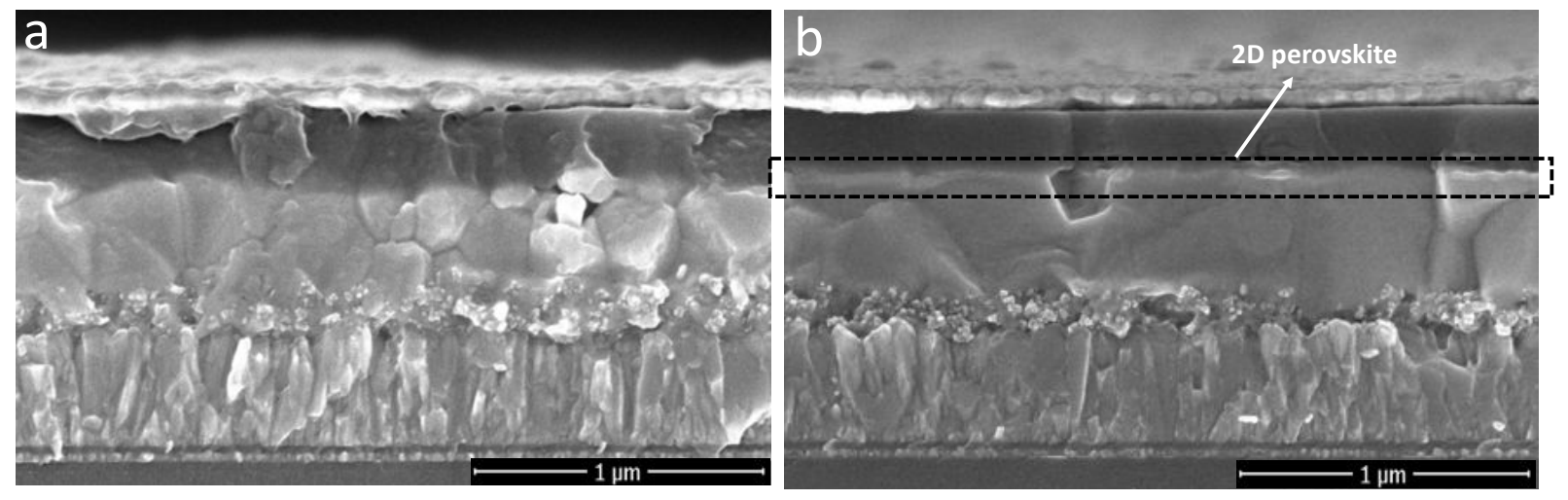

Figure S5. Cross-sectional SEM images of the (a) 3D PSCs and (b) 3D/2D PSCs. 

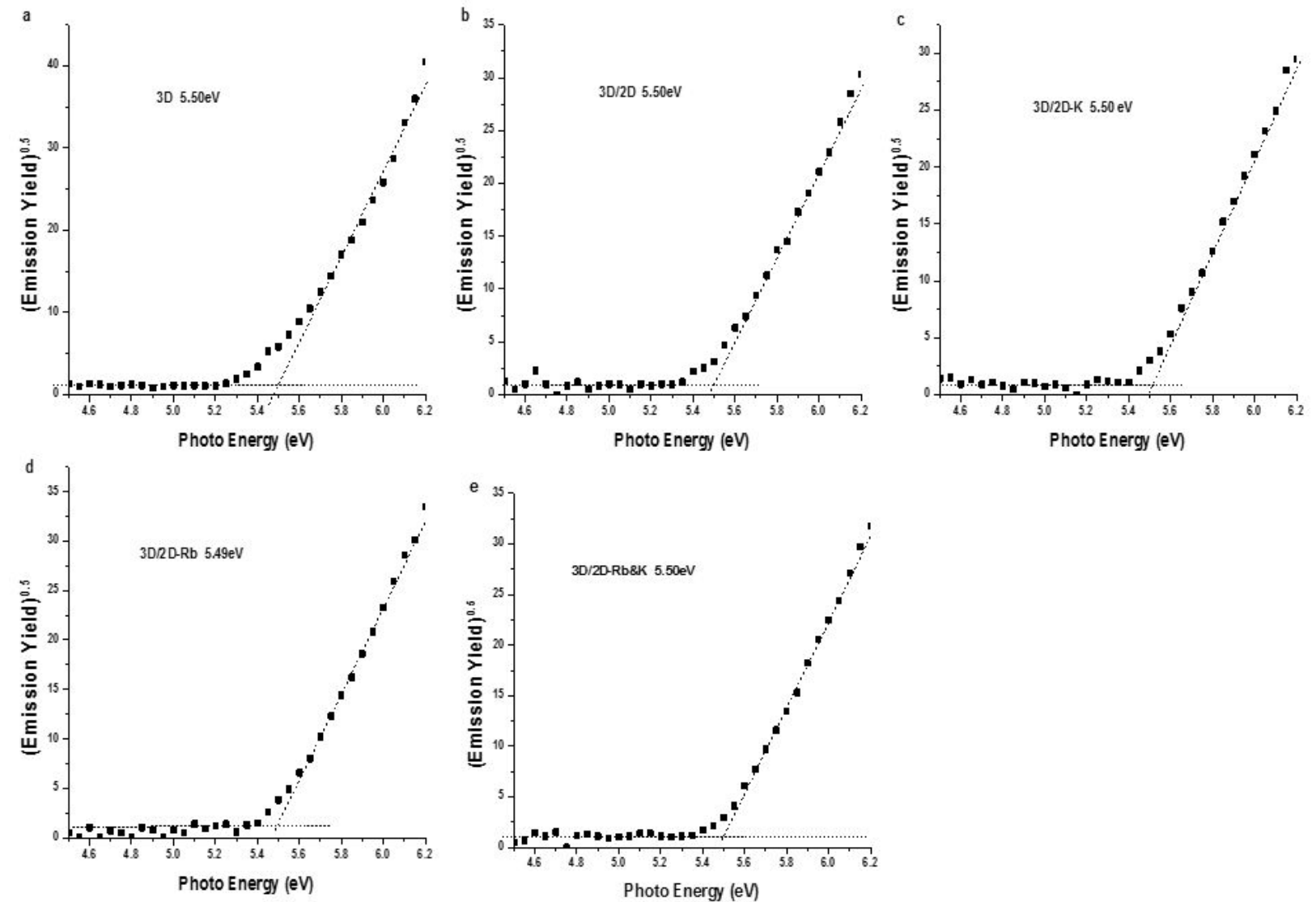

Figure S6. Photoelectron spectroscopy in air (PESA) analysis of (a) 3D, (b) 3D/2D, (c) 3D/2D-K, (d) $3 \mathrm{D} / 2 \mathrm{D}-\mathrm{Rb}$ and (e) $3 \mathrm{D} / 2 \mathrm{D}-\mathrm{Rb} \& \mathrm{~K}$. In all the $3 \mathrm{D} / 2 \mathrm{D}$ samples, BAI concentration is $10 \mathrm{mg} / \mathrm{mL}$ in IPA. For alkali cation-doped $3 \mathrm{D} / 2 \mathrm{D}$ samples, the alkali cation weight ratios with respect to BAI are $5 \% \mathrm{Rb}^{+}, 5 \% \mathrm{~K}^{+}$and $5 \% \mathrm{Rb}^{+}+5 \% \mathrm{~K}^{+}$for $3 \mathrm{D} / 2 \mathrm{D}-\mathrm{K}, 3 \mathrm{D} / 2 \mathrm{D}-\mathrm{Rb}$ and $3 \mathrm{D} / 2 \mathrm{D}-\mathrm{Rb} \& \mathrm{~K}$, respectively. 


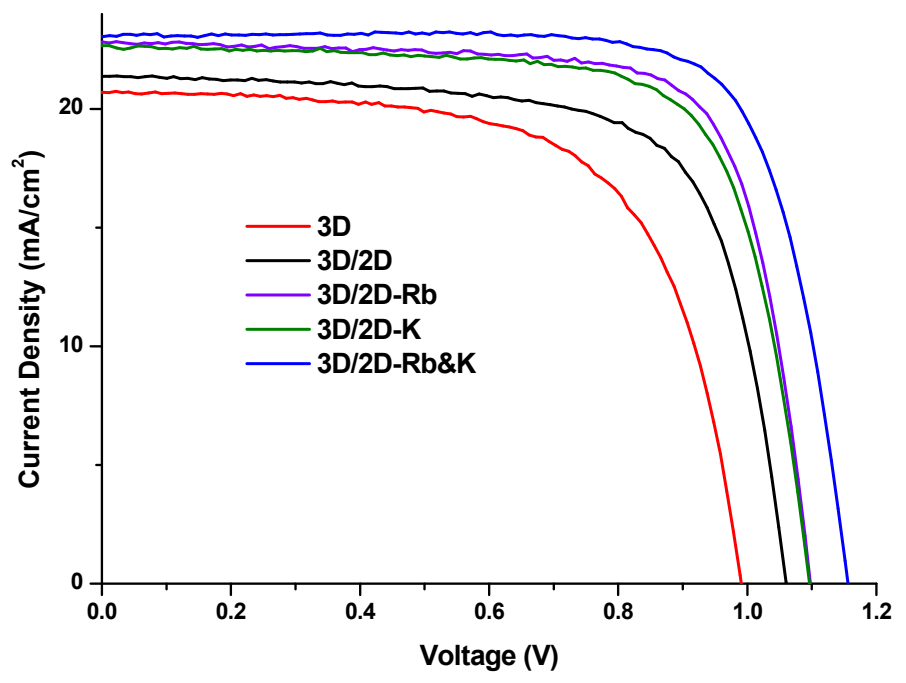

Figure S7. J-V characteristics of the PSCs forward scanning from $-0.5 \mathrm{~V}$ to $1.2 \mathrm{~V}$ at scan rate of $0.1 \mathrm{~V} / \mathrm{s}$. 


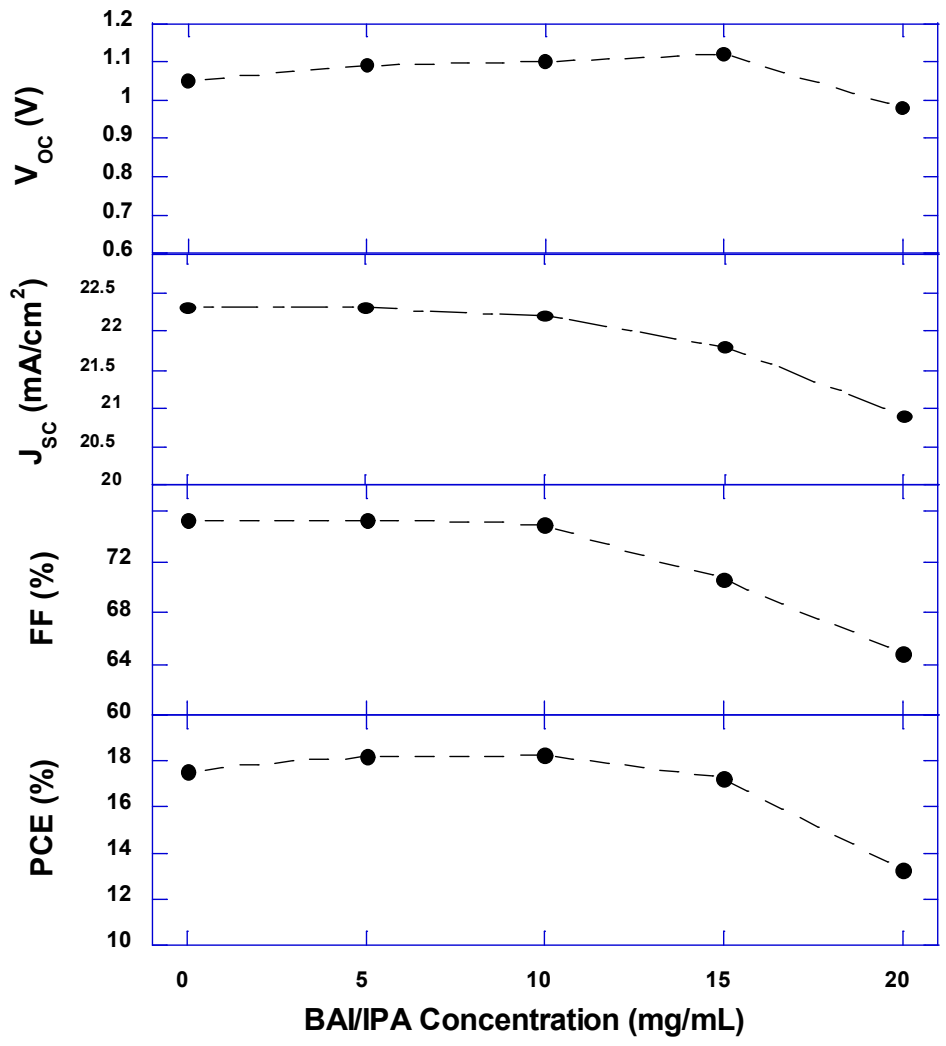

Figure S8. $\mathrm{V}_{\mathrm{OC}}, \mathrm{J}_{\mathrm{SC}}, \mathrm{FF}$ and PCE as a function of BAI/IPA concentration in PSCs based on $3 \mathrm{D} / 2 \mathrm{D}$.In all the $3 \mathrm{D} / 2 \mathrm{D}$ samples, BAI concentration is $10 \mathrm{mg} / \mathrm{mL}$ in IPA. For alkali cation-doped $3 \mathrm{D} / 2 \mathrm{D}$ samples, the alkali cation weight ratios with respect to $\mathrm{BAI}$ are $5 \% \mathrm{Rb}^{+}, 5 \% \mathrm{~K}^{+}$and $5 \%$ $\mathrm{Rb}^{+}+5 \% \mathrm{~K}^{+}$for $3 \mathrm{D} / 2 \mathrm{D}-\mathrm{K}, 3 \mathrm{D} / 2 \mathrm{D}-\mathrm{Rb}$ and $3 \mathrm{D} / 2 \mathrm{D}-\mathrm{Rb} \& \mathrm{~K}$, respectively. 

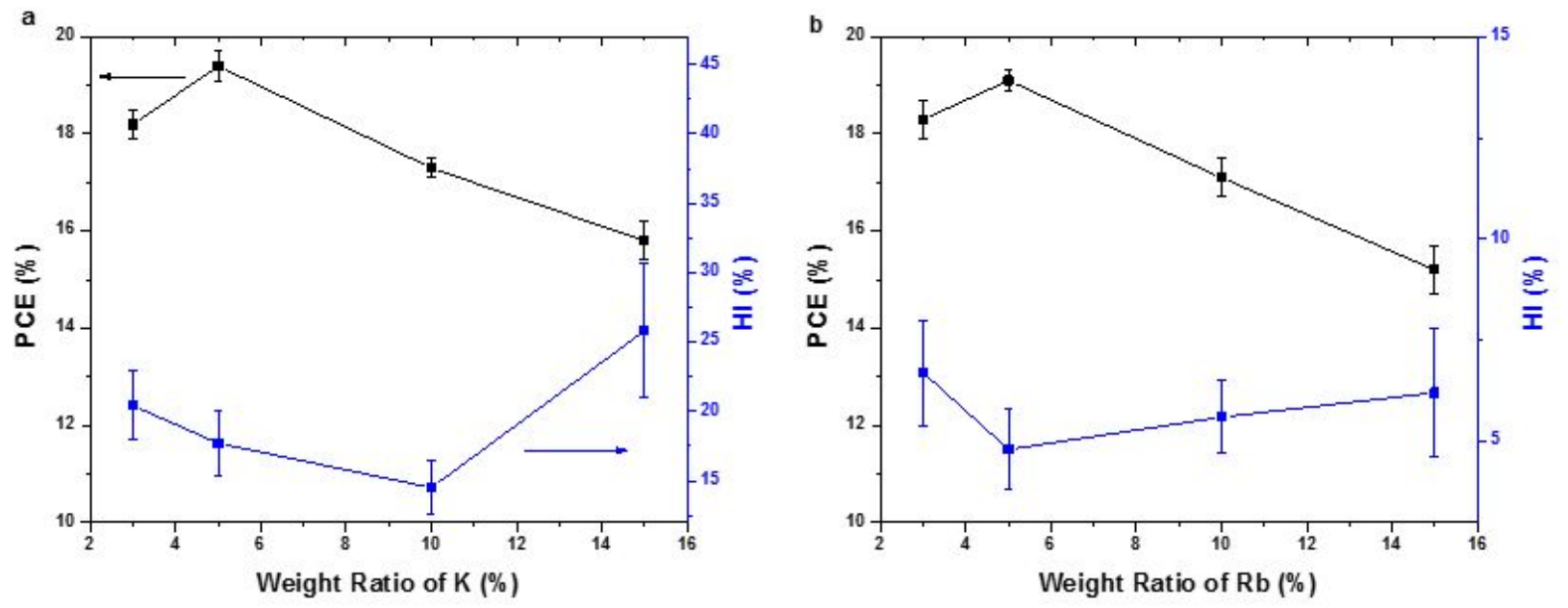

Figure S9. (a) PCE and hysteresis index (HI) as a function of weight ratio of $\mathrm{K}^{+}$in $2 \mathrm{D}$ perovskite; (b) PCE and $\mathrm{HI}$ as a function of weight ratio of $\mathrm{Rb}^{+}$in $2 \mathrm{D}$ perovskite. The concentration of BAI in IPA is $10 \mathrm{mg} / \mathrm{mL}$. 

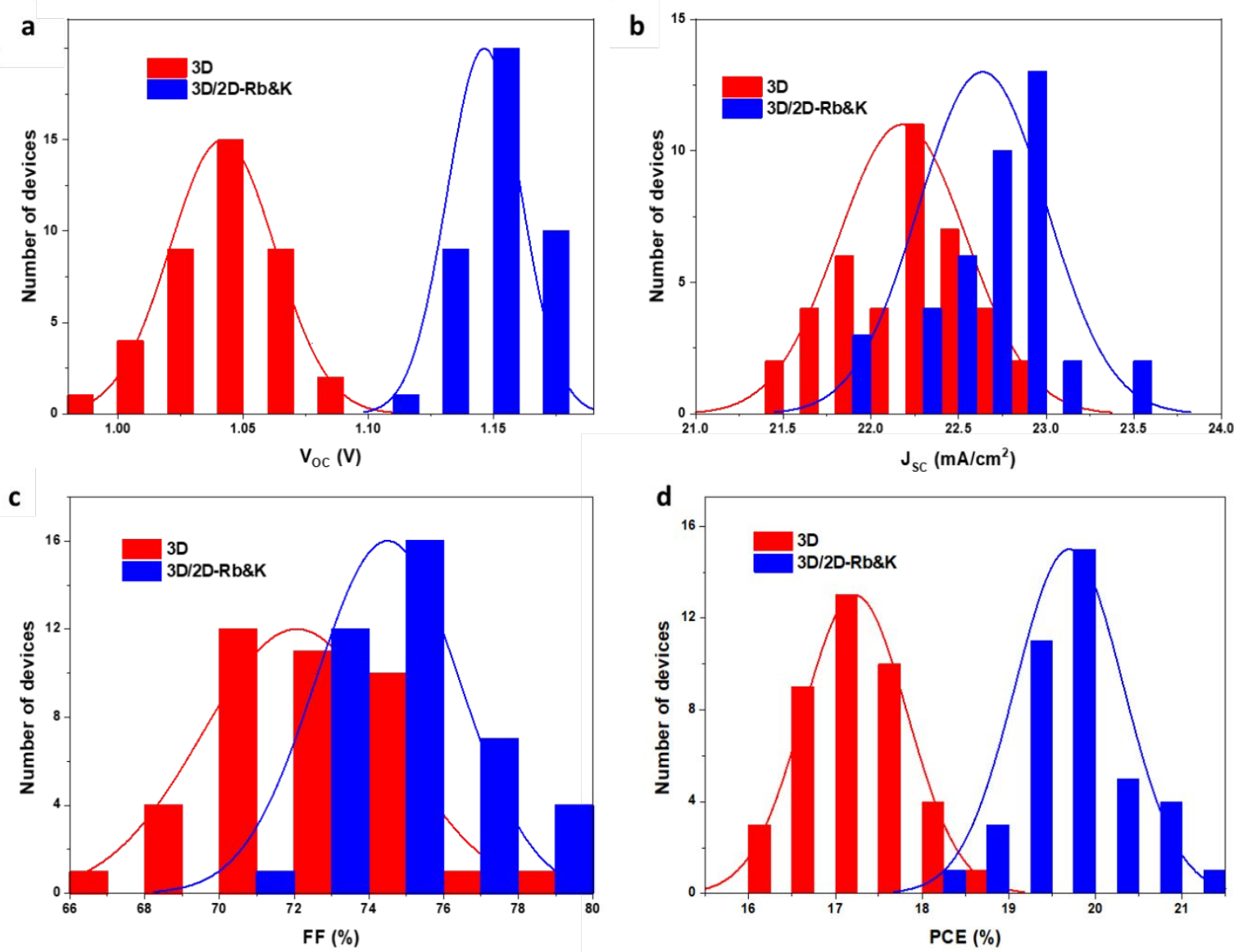

Figure S10. Statistical histograms of (a) $\mathrm{V}_{\mathrm{OC}}$, (b) $\mathrm{J}_{\mathrm{SC}}$, (c) FF and (d) PCE of PSCs based on 3D and $3 \mathrm{D} / 2 \mathrm{D}-\mathrm{Rb} \& \mathrm{~K}$, the statistical data were summarized from 40 devices for each type of PSCs. 

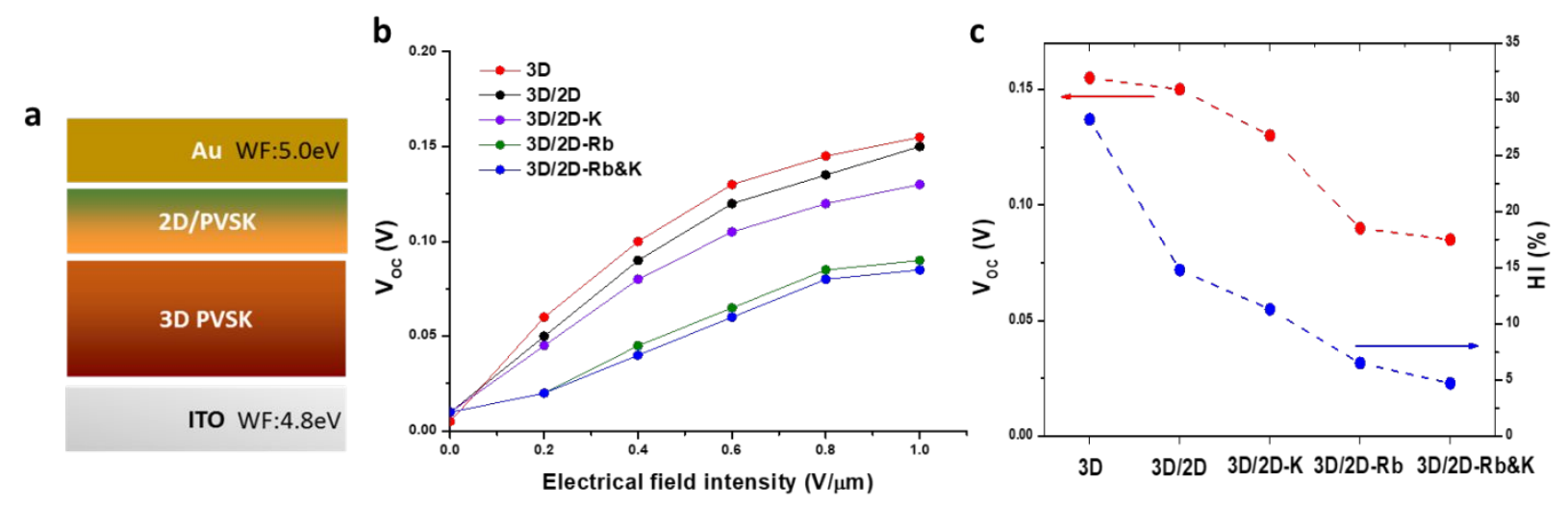

Figure S11. (a) Device structure of the quasi-symmetric conductor based on 3D/2D hybrid perovskite films, (b) $\mathrm{V}_{\mathrm{OC}}$ of the devices under different electrical field intensity. The devices were poled under external voltages for $1 \mathrm{~min}$, (c) Correlations between the VOC of the quasi-symmetric conductor under electrical field of $1 \mathrm{~V} / \mu \mathrm{m}$ and $\mathrm{HI}$ of the PSCs based 3D perovskite, 3D/2D perovskite, 3D/2D-K perovskite, 3D/2D-Rb perovskite and 3D/2D-Rb\&K perovskite. 

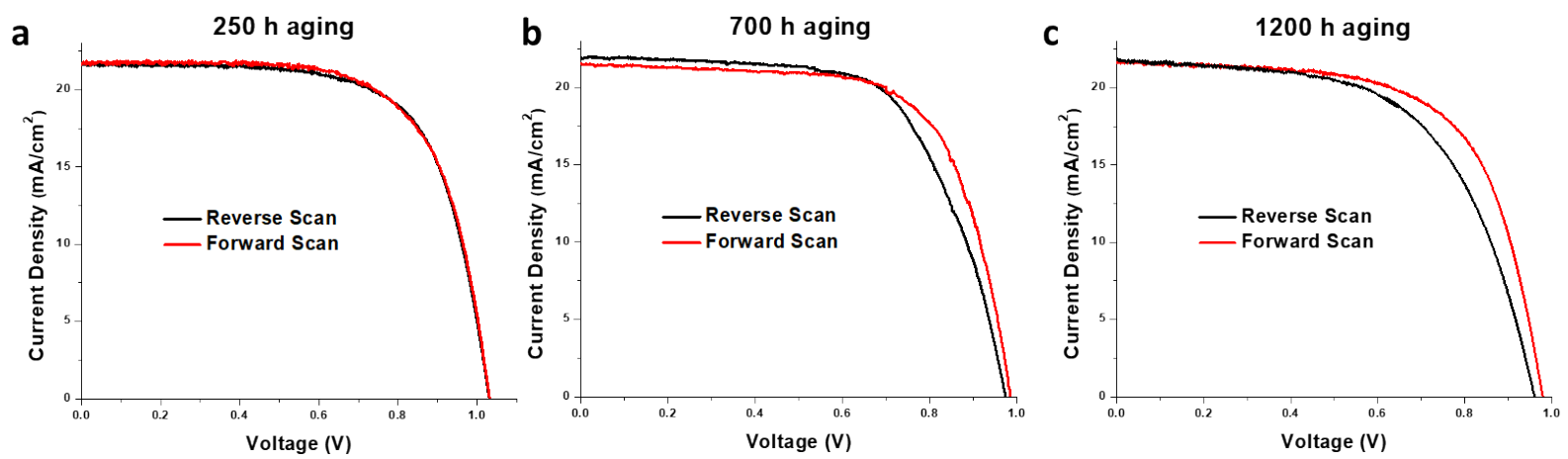

Figure S12. J-V characteristics (in both reverse and forward scan) of the 3D PSCs aged under RH of $30 \%-60 \%$ for (a) $250 \mathrm{~h}$, (b) $700 \mathrm{~h}$ and (c) $1200 \mathrm{~h}$. 

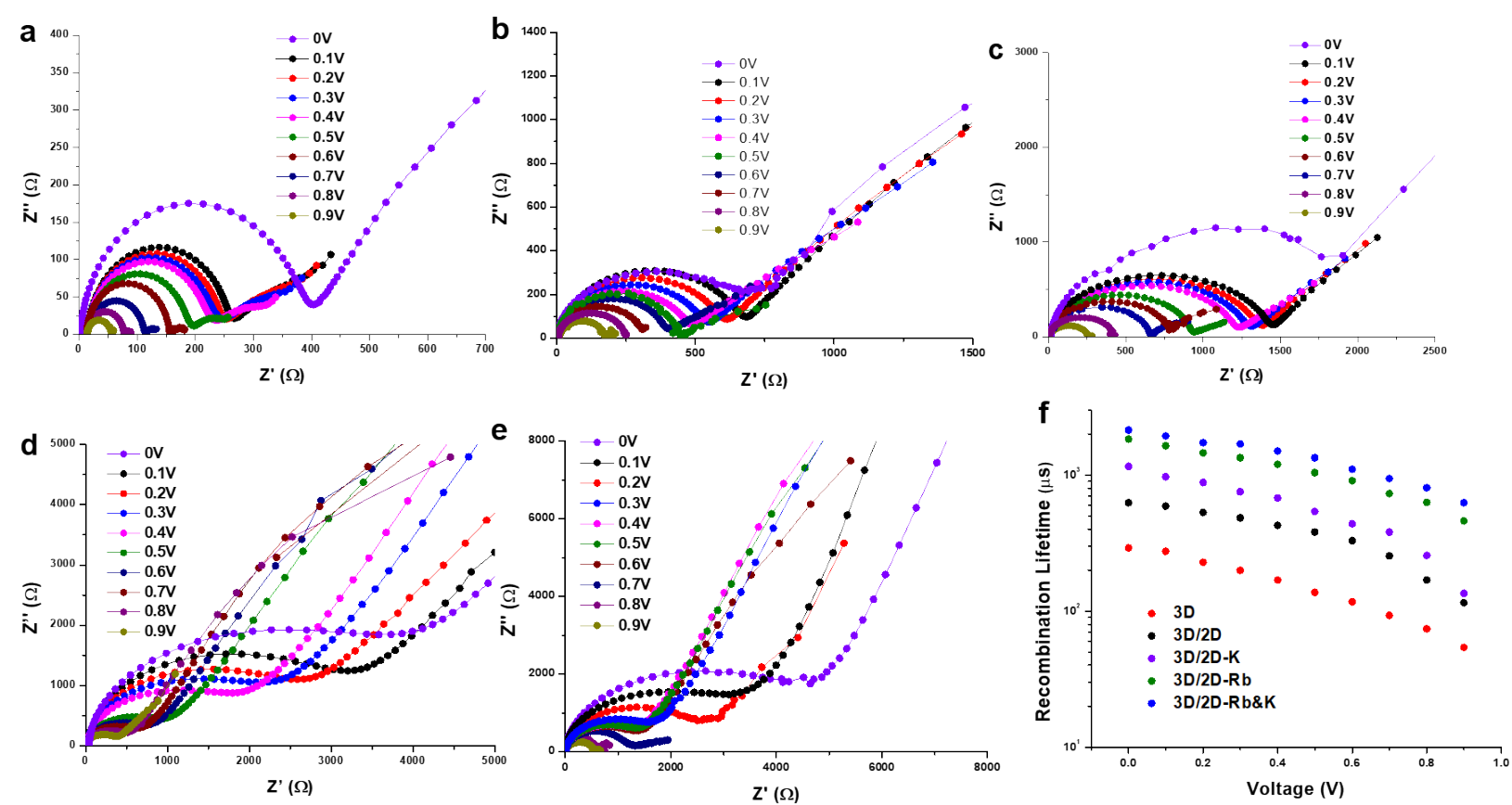

Figure S13. Nyquist plot of PSCs based on (a) 3D, (b) 3D/2D, (c) 3D/2D-K, (d) 3D/2D-Rb and (e) $3 \mathrm{D} / 2 \mathrm{D}-\mathrm{Rb} \& \mathrm{~K}$ perovskites under external bias from $0-0.9 \mathrm{~V}$; (f) Recombination lifetime of the devices extracted from the middle frequency region of the Nyquist plots $\left(\tau_{r e c}=R_{r e c} C_{g}=1 / f\right)$. 